\title{
Kernos
}

Revue internationale et pluridisciplinaire de religion grecque antique

$10 \mid 1997$

Varia

\section{R. MERKELBACH, Isis regina - Zeus Sarapis}

\section{Michel Malaise}

\section{(2) OpenEdition}

\section{Journals}

Édition électronique

URL : http://journals.openedition.org/kernos/697

DOI : $10.4000 /$ kernos. 697

ISSN : 2034-7871

Éditeur

Centre international d'étude de la religion grecque antique

Édition imprimée

Date de publication : 1 janvier 1997

Pagination : 371-372

ISSN : 0776-3824

Référence électronique

Michel Malaise, «R. meRKelbach, Isis regina - Zeus Sarapis », Kernos [En ligne], 10 | 1997, mis en ligne le 12 avril 2011, consulté le 24 septembre 2020. URL : http://journals.openedition.org/kernos/697 ; DOI : https://doi.org/10.4000/kernos.697 
Les animaux sont analysés dans la section VI ( $\mathrm{n}^{\circ}$ 264-286). Sans exclure la possibilité, pour de rares exemplaires, qu'il puisse s'agir de jouets $\left(n^{\circ} 273\right)$, L.T. préfère situer le rôle de ces petits animaux dans un climat religieux : substituts pour sacrifices d'animaux dans les temples (porc, coq) ou ex-voto. Le thème du chien est mis en rapport avec la chienne personnifiant l'étoile Sothis et qu'Isis, productrice de la crue, peut enfourcher à partir de l'époque romaine; l'animal devient ainsi signe de fertilité. Sans dénier la pertinence de cette exégèse, nous avons montré ailleurs que le chien est susceptible de multiples connotations ( $c f$. M. MALAISE, Harpocrate, la tortue et le cbien. Contribution à l'iconographie du fils d'Isis, in Bulletin de la Société Francaise d'Égyptologie, 122 [1991], p. 13-35). L'image du tilapia est, elle, assurément symbole d'auto-génération, et donc de renaissance, selon une ancienne conception égyptienne.

Enfin, les sections VII et VIII sont, respectivement, consacrées à quelques lanternes en forme de naiscos $\left(\mathrm{n}^{\circ} 287-291\right)$ et à des varia $\left(\mathrm{n}^{\circ} 292-321\right)$. Parmi ces derniers sont particulièrement dignes d'attention un naiscos monté sur quatre roues, et dont la porte est flanquée d'amphores, $\left(n^{\circ} 292\right)$ imitant les véhicules à roue qui remplacent parfois les barques processionnelles; une kliné avec paysage nilotique $\left(\mathrm{n}^{\circ} 295\right)$ et deux porte-torches miniatures ( $n^{\circ} 305-306$ ) décorés de figures ou de symboles divins.

Pour mettre un terme à notre recension de cet ouvrage fondamental, nous voudrions souligner que l'A. a choisi d'interpréter la quasi totalité des terres cuites étudiées à la lumière de préoccupations religieuses, même pour des objets d'apparence banale et tirés du monde profane. Cette constatation essentielle rejoint les récentes et intéressantes considérations émises par G. NACHTERGAEL, CdE, 79 (1995), p. 263-268. Sur cette question, comme sur bien d'autres, la publication d'un maximum de terres cuites permettra de cerner de mieux en mieux chronologie et signification d'une documentation qui nous plonge de façon extraordinaire et vivante dans le monde vécu et imaginaire de l'Égypte gréco-romaine. L'ouvrage de L.T. est une contribution d'importance à ce travail de restauration.

Michel MALAISE

(Université de Liège)

\section{Reinhold MERKELBACH, Isis regina - Zeus Sarapis. Die griechisch- ägyptische Religion nach den Quellen dargestellt, Stuttgart-Leipzig, 1995.} 1 vol. $19 \times 25,3 \mathrm{~cm}$, XXVIII+722 p., 35 dessins, 252 fig. et 8 pl. couleurs hors-texte. ISBN 3-519-07427-3.

Le titre de cet ouvrage est relativement trompeur car il annonce une synthèse de la religion isiaque, alors qu'en réalité le livre, composé de deux grandes parties bien distinctes, a été écrit pour défendre une thèse que l'A. avait déjà développée dans Roman und Mysterium en 1962. Selon cette thèse, plusieurs romans d'époque impériale seraient en fait des romans à clef, écrits pour des isiaques. Pour donner une plus large base à sa " démonstration », R.M. a entrepris d'écrire ce livre dont la première partie, la plus volumineuse (p. 57-334), nous retrace une vue d'ensemble des cultes isiaques, depuis la haute époque hellénistique jusqu'à leur disparition devant le christianisme triomphant. Le panorama est fondé sur une documentation variée, mais l'A. privilégie documents littéraires et arétalogiques, c'est-à-dire une vision assez érudite et moins proche des réalités quotidiennes que celle obtenue à la lecture des 
inscriptions. Il en résulte une exagération de l'hellénisation, surtout d'Isis, qui conduit l'A. à écrire que « du mélange de l'égyptien Sarapis avec le grec Zeus, d'Isis avec Déméter, d'Harpocrate avec Éros, est née une nouvelle religion » (p. vI). Le jugement est également faussé par un manque de perspective diachronique et géographique. Isis a changé avec le temps et les lieux. On regrettera aussi des lacunes dans la bibliographie la plus récente. Par exemple, une lecture plus attentive des recherches consacrées aux arétalogies aurait sans doute empêché R.M. de caractériser les arétalogies comme «durch und durcb griecbisch-rationalistich» (p. 119). En dehors de l'analyse des grandes figures de la sainte famille d'Isis, le lecteur trouvera également étudiés les nombreux aspects cultuels et la diffusion des cultes isiaques à travers le monde antique.

Deux chapitres sont réservés à l'interprétation philosophique de la religion égyptienne à la lumière du stoïcisme et du platonisme. À cet égard, remarquable est le traité de Plutarque. Son analyse néoplatonicienne du mythe d'Isis et Osiris débouche, cette fois de façon incontestable, sur un système plus grec qu'égyptien. Suit l'analyse du livre $\mathrm{XI}$ des Métamorphoses d'Apulée, une source essentielle pour notre connaissance des cultes isiaques. Les commentaires de R.M. nous semblent cependant souvent audacieux. Il faut, par exemple, beaucoup de bonne volonté pour trouver dans le récit de la première initiation de Lucius des rites analogues à ceux que nous décrit le chapitre 125 du Livre des Morts, tout en ajoutant que l'épisode de la vision du soleil en pleine nuit n'est pas égyptien, mais une transposition rituelle de l'illumination platonicienne. Cette première partie se termine par le récit de déclin, puis de la disparition des cultes isiaques, qui, selon l'A., n'auraient pu rivaliser avec le christianisme pour avoir renoncé à poursuivre dans la voie d'une interprétation philosophique grecque.

La seconde partie de l'étude (p. 335-484) tente de démontrer le caractère allégorique des romans d'amour et de voyage de Xénophon d'Éphèse et d'Achille Tatius, de l'Historia Apollonii regis Tyri et des Métamorphoses d'Apulée. Les tribulations connues par les héros de ces quatre cuvres seraient en fait des transpositions et des variations sur le mythe d'Isis et d'Osiris. Pareils romans à clef auraient puisé à deux sources d'inspiration. D'abord, une série de thèmes seraient à relier aux rites d'initiation et à des scènes jouées à cette occasion. Les multiples malheurs que subissent les héros de ces romans ne seraient eux-mêmes qu'une image des épreuves qui attendent l'initié. Les récits des miracles accomplis par les dieux égyptiens constitueraient une seconde source car on trouve autant dans les arétalogies que dans les romans étudiés les mêmes réactions psychologiques face à l'intervention divine. À l'aide de ces clefs, R.M. décrypte ensuite systématiquement les divers épisodes des romans. Nous avouerons ne pas avoir été convaincu par la « démonstration», trop systématique, trop subtile, où plus rien n'est à prendre au premier degré. Si l'on veut jouer avec les multiples virtualités des mythologies anciennes, et conférer à chaque fait, élément ou lieu une valeur allégorique, il devient toujours possible de retrouver ce que l'on cherche.

La dernière partie de l'ouvrage est réservée à une remarquable documentation iconographique de 252 illustrations de haute qualité que rassemblent les pages 485-692. Des index faciliteront la tâche du lecteur.

En résumé, si la thèse ici présentée ne nous a pas convaincu, il reste que la première partie de ce livre offre un large panorama des cultes isiaques. 